\title{
Stereotactic hypothalamotomy for behaviour disorders
}

\author{
J. R. SCHVARCZ, ${ }^{1}$ R. DRIOLlET, E. RIOS, AND O. BETTI
}

From the Institute of Neurosurgery of the University of Buenos Aires, Argentina

SUMMARY Posterior hypothalamotomy is a relatively simple stereotactic procedure. The radiological determination of the target and its physiological corroboration by electrical stimulation are $\frac{\bar{O}}{\omega}$ accurate. The lesions have always been made in the site of maximum sympathetic response. In this respect, the cardiovascular changes (hypertension and tachycardia), which are always elicited from a more restricted area, are of particular importance. Depth recordings, however, have been less useful. ${ }^{\text {os }}$ Undesirable side-effects, if present, were mild and transitory. There was no postoperative. intelligence deficit, at least with the standard tests.

Soon after the suggestion that particular areas of the brain were involved in emotional behaviour, Bard (1928) showed that removal of all nervous tissue rostral, dorsal, and lateral to the hypothalamus did not abolish sham rage phenomena in decorticate preparations. However, sections caudal to the hypothalamus eliminated this response (Bard and Rioch, 1937; Bard, 1939).

Hess, in 1927, using chronically implanted electrodes in cats, elicited a wide variety of 'affective-defensive' reactions from hypothalamic stimulation, which were of somatic, autonomic, and behavioural type. These purposeful and well coordinated responses could be obtained from a relatively extensive area, although with lower threshold from the perifornical region (Hess, 1954, 1969).

Later papers suggest that a wide variety of behavioural patterns depend upon relatively specific hypothalamic structures (Ranson and Magoun, 1939; Masserman, 1941 ; Ingram, 1952, 1958; Fernandez de Molina and Hunsperger, 1962; Egger and Flynn, 1962, 1967).

Because other psychosurgical procedures for aggressive behaviour produced uncertain results and a considerable number of undesirable sideeffects, we were induced to make posterior hypothalamic lesions (Schvarcz, Driollet Laspiur, and Betti, 1968; Schvarcz, 1970), based largely on the work of Sano (1966) and Sano, Yoshioka, Ogashina, Ishijima, and Ohye (1966), Sano, Yoshioka, Ogashina, Ishijima, Ohye, Sekino,

1 Present address: Department of Surgical Neurology, University of Edinburgh. and Mayanagi (1967), who made lesions of the ergotropic area of the hypothalamus. Spiegef or Wycis, Freed, and Orchinik (1953) have als $\omega$ performed lateral hypothalamotomies, althoug (N) with other associated targets apart from two cases (Spiegel and Wycis, 1967).

\section{METHODS}

All patients were operated upon under genea⿳亠口冋 anaesthesia using Riechert's stereotactic apparatư⿱乛亅. N The third ventricle was outlined by lumbar pneumoencephalography. A concentric bipolar tungsten electrode, capable of stimulation and lesion making, of $1 \mathrm{~mm}$ external diameter with an interpolar dis-o tance of $1.5 \mathrm{~mm}$, asymmetrically insulated, was passed $\overparen{\mathrm{D}}$ through a prefrontal burr hole. The lesion was made with fractionated electrocoagulation, and its diametero을 estimated as $3-4 \mathrm{~mm}$.

The target point chosen was $3 \mathrm{~mm}$ perpendicularly below the midpoint of the intercommissural line and $2 \mathrm{~mm}$ from the lateral wall of the third ventricle (Figure, a, b) which corresponds to the medial parto of the posterior hypothalamic area.

The ventromedial nucleus was carefully avoided, since lesions in this situation produce savage be-O haviour in experimental animals (Wheatley, 1944). The lateral hypothalamic area was also avoided,응 since a lesion involving this area may produce dis- $\rightarrow$ orders of food (Anand and Brobeck, 1951; Anand, 1961) and water intake (Andersson and McCann, 1955; Andersson, Jewell, and Larsson, 1958) and thermoregulation (Ranson, Fisher, and Ingram, $\mathcal{O}$ 1937). Finally, the mamillothalamic tract must be avoided because of the risk of memory disorders.

Electrical stimulation was done in all cases fot

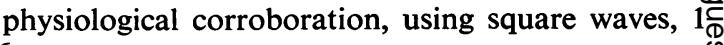



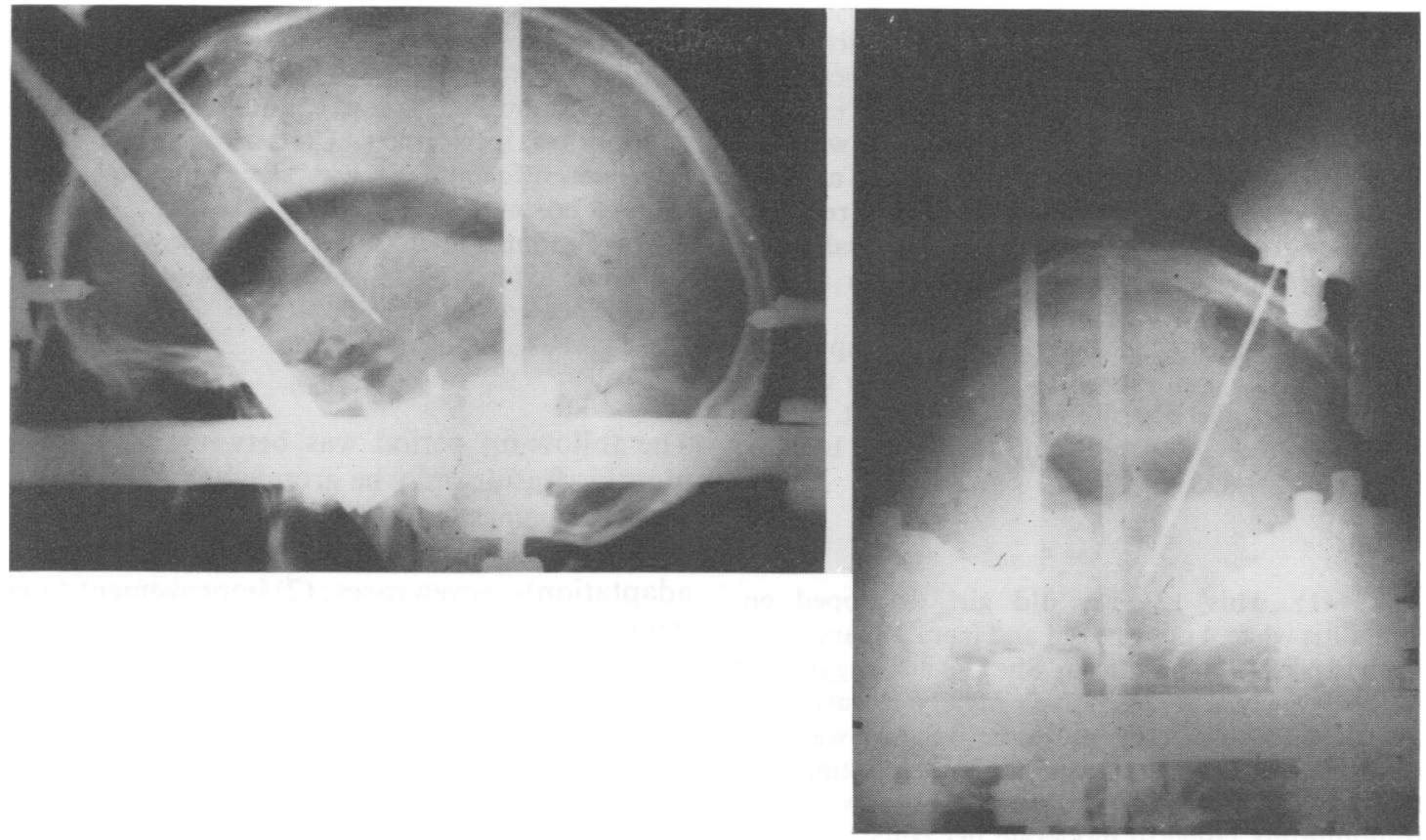

(a)

(b)

FIGURE Lateral (a) and anteroposterior (b) radiographs with the electrode in place.

msec, 5 to $20 \mu V, 100$ to $300 \mathrm{c} / \mathrm{sec}$. This type of stimulus produced an arousal reaction, with opening of the eyelids and vocalization, and autonomic responses, including both unilateral or bilateral midriasis, and marked hypertension and tachycardia, usually with tachypnoea. These changes disappeared approximately two minutes after the end of the stimulation. In addition, there were certain somatic responses-namely, convergent strabismus and/or downward deviation of the gaze, generally with ipsilateral predominance, as well as tonic ipsiversive movements.

Lesions were always made at the site of the strongest sympathetic responses, paying particular attention to the cardiovascular changes (hypertension, tachycardia) elicited from a more restricted area. Depth recordings, however, were less useful.

Subsequently the area of the lesion was plotted in respect to the target chosen and the site of maximal cardiovascular response. The maximum corrections required were less than $3 \mathrm{~mm}$ in the anteroposterior plane, $2 \mathrm{~mm}$ in the vertical, and $1 \mathrm{~mm}$ in the lateral. Stimulation responses were particularly precise in regard to the lateral coordinates, so that along a strip $5 \mathrm{~mm}$ from the ventricular wall parasympathetic responses, of hypotension, bradycardia, and sometimes miosis, were always obtained.

\section{PATIENTS}

Twenty-one hypothalamic lesions have been made in 11 cases. Bilateral lesions have always been made, with an average interval of 10 days, except in the first patient, who had a unilateral lesion only.

All the patients had suffered episodes of severe hetero- and/or auto-aggressiveness, usually with violent, destructive behaviour. In most cases the patient's families were quite unable to cope with the situation and often they were dangerous either to the public or to themselves during these attacks. In all cases extensive psychiatric treatment had failed.

Of the 11 cases, two were diagnosed as simple aggression with psychopathic personality. One patient suffered from schizophrenia. The remaining eight patients were epileptics, five of whom were oligophrenics, with marked hyperactivity in two of them.

In this series, two cases had postoperative hypersomnia, lasting 3 to 10 days. Another case developed persistent tachycardia of $120 / \mathrm{min}$ over five days, with, however, a normal blood pressure.

\section{CASE 1}

(R.15147) This 20 year old man was diagnosed as having a psychopathic personality. He had a long history of aggressiveness and social inadaptability, with violent outbursts of temper, threatening his relatives with guns on several occasions and having frequent motiveless street quarrels with strangers. $\mathrm{He}$ had been in gaol on several occasions and his 
family was quite unable to cope with this situation. His intelligence quotient was normal and there were no EEG abnormalities.

In July 1967 a right hypothalamotomy was performed. The size of the lesion was estimated as $4 \mathrm{~mm}$ in diameter. The immediate post-operative response was very good and he became quiet and calm. We decided therefore to wait before doing a contralateral lesion, since this was our first case.

This good result has been maintained up to the present and he is now living with his family without any problems and is well integrated within it. He has had no further convictions and there have been no more outbursts.

\section{CASE 4}

(R.15441) This 12 year old girl developed encephalitis when 4 months old and from 3 years of age she had progressive erethism. She was auto-aggressive as well as hetero-aggressive, mainly towards her relatives, being extremely destructive. She was very restless and hyperactive, running and shouting continually. High doses of anticonvulsants as well as tranquillizers failed to moderate her behaviour.

In May 1968 bilateral hypothalamotomy was performed with a two week interval. Postoperatively her behaviour improved, but within a month her restlessness had reappeared. There was very little improvement with tranquillizers, although she was less hyperkinetic.

The case is regarded as a failure.

\section{CASE 5}

(R.15669) This 18 year old boy had a long history of aggressive, destructive behaviour. He killed or buried alive different domestic animals and attempted two or three times to set light to his house. He had also assaulted his mother on several occasions. Because of convulsions of grand-mal type he required anticonvulsant therapy.

In October 1968 bilateral hypothalamic lesions were performed with an interval of five days. After the second lesion there was a postoperative hypersomnia which lasted three days, clearing spontaneously. There was improvement in his behaviour which became quiet, calm and manageable. $\mathrm{He}$ is now living at home.

\section{CASE 9}

(R.16113) This 32 year old patient was an aggressive schizophrenic. He had been in a mental hospital for the past 12 years, being in solitary confinement because of his extremely violent and aggressive behaviour

In July 1969 a right hypothalamotomy was performed. The immediate postoperative results were good, and he became calm and manageable. Five days after the operation he was sent back to the
Psychiatric Institute, and started living in the com mon ward with no aggressive crises. Two weeks later he was readmitted and a contralateral hypothala $\Phi$ motomy was performed. The postoperative course was uneventful and he was again returned to his original hospital.

Three months later he was discharged home, and he is now living with his family without evidence of aggression.

\section{RESULTS}

The follow-up period was between six and $48_{0}^{5}$ months. Results may be grouped into three cate gories: (1) marked improvement (without aggres $\frac{\overline{\bar{s}}}{\frac{1}{2}}$ sive crises or violent behaviour, with social re $\frac{\mathbb{D}}{2}$ adaptation) - seven cases; (2) improvement (nowes controlled by drugs) - three cases; (3) failureone case.

The best results have been obtained in patientsw with normal intelligence, although they have been less satisfactory in the oligophrenic anष्छ hyperkinetic patients.

\section{REFERENCES} Anand, B. K. (1961). Nervous regulation of food intateo
Physiological Reviews, 41, 677-708.

Anand, B. K., and Brobeck, J. R. (1951). Hypothalamic \&的trol of food intake in rats and cats. Yale Journal of Biolog and Medicine, 24, 123-140.

Andersson, B., and McCann, S. M. (1955). A further stud of polydipsia evoked by hypothalamic stimulation in goat. Acta Physiologica Scandinavica, 33, 333-346.

Andersson, B., Jewell, P. A., and Larsson, S. (1958). Aq appraisal of the effects of diencephalic stimulation of conscious animals in terms of normal behaviour. In Cibs Foundation symposium on the Neurological Basis of Be $\bar{\partial}$ haviour, pp. 76-89. Edited by G. E. W. Wolstenholme and C. M. O'Connor. Churchill: London.

Bard, P. (1928). A diencephalic mechanism for the expressio: of rage with special reference to the sympathetic nervoust system. American Journal of Physiology, 84, 490-515.

Bard, P. (1939). Central nervous mechanisms for emotiona? behavior patterns on animals. Research Publications Association for Research in Nervous and Mental Disease, 19. 190-218.

Bard, P., and Rioch, D. McK. (1937). A study of four cat? deprived of neocortex and additional portions of the fore brain. Johns Hopkins Hospital Bulletin, 60, 73-147.

Egger, M. D., and Flynn, J. P. (1962). Amygdaloid sup 3 pression of hypothalamically elicited attack behaviori Science, 136, 43-44.

Egger, M. D., and Flynn, J. P. (1967). Further studies on the effects of amygdaloid stimulation and ablation on hypo응 thalamically elicited attack behavior in cats. In Structure and Function of the Limbic System. Edited by W. R. Ade and T. Tokizane. Progress in Brain Research, 27, 165-182 Elsevier: Amsterdam.

Fernandez de Molina, A., and Hunsperger, R. W. (1962)? Organization of the subcortical system governing defenced and flight reactions in the cat. Journal of Physiology, 1600

Hess, W. R. (1954). Diencephalon: Autonomic and Extra? pyramidal Function. Grune and Stratton: New York.

Hess, W. R. (1969). Hypothalamus and Thalamus: Experi mental Documentation. Thieme: Stuttgart. 
Ingram, W. R. (1952). Brain stem mechanisms in behavior. Electroencephalography and Clinical Neurophysiology, 4, 397-406.

Ingram, W. R. (1958). Modification of learning by lesions and stimulation in the diencephalon and related structures. In Reticular Formation of the Brain, pp. 535-544. Edited by H. Jasper, L. O. Proctor, R. S. Knigton, W. C. Noshay, and R. T. Costello. Little, Brown: Boston.

Masserman, J. H. (1941). Is the hypothalamus a center of emotion? Psychosomatic Medicine, 3, 3-25.

Ranson, S. W., Fisher, C., and Ingram, W. R. (1937). Hypothalamic regulation of temperature in the monkey. Archives of Neurology and Psychiatry, 38, 445-466.

Ranson, S. W., and Magoun, H. W. (1939). The hypothalamus. Ergebnisse der Physiologie, biologischen Chemie und experimentellen Pharmakologie, 41, 56-163.

Sano, K. (1966). Sedative stereoencephalotomy: fornicotomy, upper mesencephalic reticulotomy and postero-medial hypothalamotomy. In Correlative Neurosciences. Part B, Clinical studies. Edited by T. Tokizane, and J. P. Schadé. Progress in Brain Research, 21B, 350-372. Elsevier: Amsterdam.

Sano, K., Yoshioka, M., Ogashiwa, M., Ishijima, B., and Ohye, C. (1966). Postero-medial hypothalamotomy in the treatment of aggressive behaviors. Confinia Neurologica, 27, 164-167.

Sano, K., Yoshioka, M., Ogashiwa, M., Ishijima, B., Ohye, C., Sekino, H., and Mayanagi, Y. (1967). Autonomic, somatomotor and electroencephalographic responses upon stimulation of the hypothalamus and the rostral brain stem in man. Confinia Neurologica, 29, 257-261.

Schvarcz, J. R., Driollet Laspiur, R., and Betti, O. O. (1968). Introduction a la cirugia del hipotalamo posterior. Bol. Asoc. Arg. Neurocir., 4, 49.

Schvarcz, J. R. (1970). Stereotactic hypothalamotomy for agressive behaviour. Balado. Neurosurgical Prize,University of Buenos Aires.

Spiegel, E. A., Wycis, H. T., Freed, H., and Orchinik, C. (1953). Thalamotomy and hypothalamotomy for the treatment of psychoses. Research Publications, Association for Research in Nervous and Mental Disease, 31, 379-391.

Spiegel, E. A., and Wycis, H. T. (1967). Multiple representation of various functions in the human subcortex. Confinia Neurologica, 29, 163-167.

Wheatley, M. D. (1944). The hypothalamus and affective behavior in cats. Archives of Neurology and Psychiatry, 52, 296-316. 